\title{
СТРУКТУРА КЛАСТЕРНОГО РАЗВИТИЯ ПРОМЫШЛЕННОСТИ СЕВЕРО-ЗАПАДНОГО ФЕДЕРАЛЬНОГО ОКРУГА
}

\section{(c) 2018 Карпичев Евгений Владимирович}

кафедра экономики и управления предприятиями и производственными комплексами

Санкт-Петербургский государственный экономический университет

191023, Санкт-Петербург, Садовая ул., д. 21

E-mail:kev@szfo.gov.ru

В настоящей публикации представлен авторский взгляд в рамках научной дискуссии о соответствии профиля кластерных объединений промышленности перспективной структуре производительных сил и производственных отношений Северо-западного федерального округа. Первично обсуждается актуальная и перспективная отраслевая структура промышленности региона. Вторично предложено видение складывающейся структуры кластеров, ее соответствие индустриальному профилю СЗФО. Исследование построено на сопоставлении актуальных данных «Эксперт Северо-запад Топ 250» (2018) и «Российской кластерной обсерватории» (2018).

Ключевые слова: кластеры, экономика промышленности.

Формирование региональных стратегий и политик промышленных агломераций является одной из приоритетных задач реального сектора экономики, направленной на формирование направлений, рамок и стимулов локальных кластерных инициатив. Актуальность данной задачи определяется «начальным» этапом развития большинства территориальных промышленных агломераций, на котором возможно выработать перспективные эффективные организационно-управленческие принципы и механизмы внутренней и внешней кооперации субъектов кластеров. Объективно понимание, что принципы кластерного развития во многом определяются специфическими экономическими, социальными и пространственными факторами конкретного региона. В настоящей публикации автор предлагает обсуждение кластерного развития промышленности Северо-западного федерального округа.

Теоретическое осмысление поставленного вопроса (кластерная структура СЗФО) отражено в исследованиях российских ученых-экономистов. Николаев М.А., Махотаева М.Ю. (2016, [6]), Лебедева Н.А. (2014, [3]), Ускова Т.В., Барабанов А.С., Попова О.И., Иогман Л.Г., Ильин В.В. (2010, [11]) рассматривали пространственные аспекты кластерного развития СЗФО, а Махотаева М.Ю., Бакуменко О.А. (2017, [5]) - межотраслевое кластерное взаимодействие в регионе. Отдельные публикации посвящены исследованию отраслевых кластеров региона: Гришин С.Ю., Ткачев В.А. (2016, [2]), Печерица Е.В. (2013, [7]) - туристский; Тимошенко С.А. (2017, [10]), Степанова Г.И. (2016, [9]) - сельскохозяйственные; Порозов П.Е., Авдеев Ю.М., Мокрецов Ю.В., Хамитова С.М., Лукашевич В.М. (2018, [8]), Летовальцева М.А. (2014, [4]) - лесоводство, деревообработка, ЦБП. Но во множестве аспектов теоретического обсуждения заявленной проблематики автор видит первичным вопрос о соответствии профиля кластерных объединений промышленности перспективной структуре производительных сил и производственных отношений СЗФО, который пока не нашел объективного отражения в научной дискуссии.

Исторически ядро промышленности СЗФО образовывали машиностроение, судостроение, химическая и лесная промышленность, а при переходе к постиндустриальной экономике на передний план (с позиции инвестиционной привлекательности) вышли высокотехнологичные отрасли: фармацевтика, информационно-коммуникационные технологии и приборостроение. Отраслевая структура СЗФО, раскрываемая через финансовые показатели «Эксперт Северо-запад Топ 250» промышленных предприятий региона, представлена в табл. 1.

С позиции анализа отраслевой структуры по обороту и чистой прибыли лидируют металлургия и АПК, но при фокусе на крупнейших игроков рынка (рисунок 1) обнаруживаются «Северсталь» и «ОСК», представляющие металлургию и судостроение, соответственно. Концентрация производств в данных отраслях, выражает как историческую тенденцию, так и перспективы 
Таблица 1. Отраслевая структура СЗФО 2017 года, раскрываемая через финансовые показатели ТоП 250 промышленных предприятий региона. Интерпретирован и статистически обработано автором на основе данных «Эксперт Северо-запад Топ 250»". Обозн.: «ВА» (\%) - вертикальный анализ по соответствующей позиции; «Q»- финансовый показатель, млн. руб.

\begin{tabular}{|c|c|c|c|c|c|c|}
\hline \multirow{2}{*}{ Отрасль } & \multicolumn{2}{|c|}{ Выручка } & \multicolumn{2}{|c|}{ Инвестиции } & \multicolumn{2}{|c|}{ Чистая прибыль } \\
\hline & Q & BA & Q & $\mathrm{BA}$ & Q & $\mathrm{BA}$ \\
\hline Металлургия & 499274 & 8,1 & 37471 & 3,9 & 82657 & 12,7 \\
\hline АПК & 479617 & 7,8 & 53871 & 5,6 & 40879 & 6,3 \\
\hline Автомобилестроение & 453177 & 7,4 & 8796 & 0,9 & 23846 & 3,7 \\
\hline Судостроение & 433672 & 7,0 & 10052 & 1,0 & 16457 & 2,5 \\
\hline Деревообрабатывающая промышленность & 368449 & 6,0 & 96500 & 9,9 & 51796 & 8,0 \\
\hline Химическая промышленность & 329984 & 5,4 & 140039 & 14,4 & 62667 & 9,7 \\
\hline IT и приборостроение & 179034 & 2,9 & 232869 & 24,0 & 20721 & 3,2 \\
\hline Энергомашиностроение & 112713 & 1,8 & 8191 & 0,8 & 12745 & 2,0 \\
\hline Машиностроение & 96522 & 1,6 & 4349 & 0,4 & 7979 & 1,2 \\
\hline Производство строительных материалов & 95817 & 1,6 & 5779 & 0,6 & 8003 & 1,2 \\
\hline Добыча полезных ископаемых & 31938 & 0,5 & 3723 & 0,4 & 7288 & 1,1 \\
\hline
\end{tabular}

* Режим доступа http://expertnw.ru/Business-panorama/reyting-top-250-2018 13.12.2018

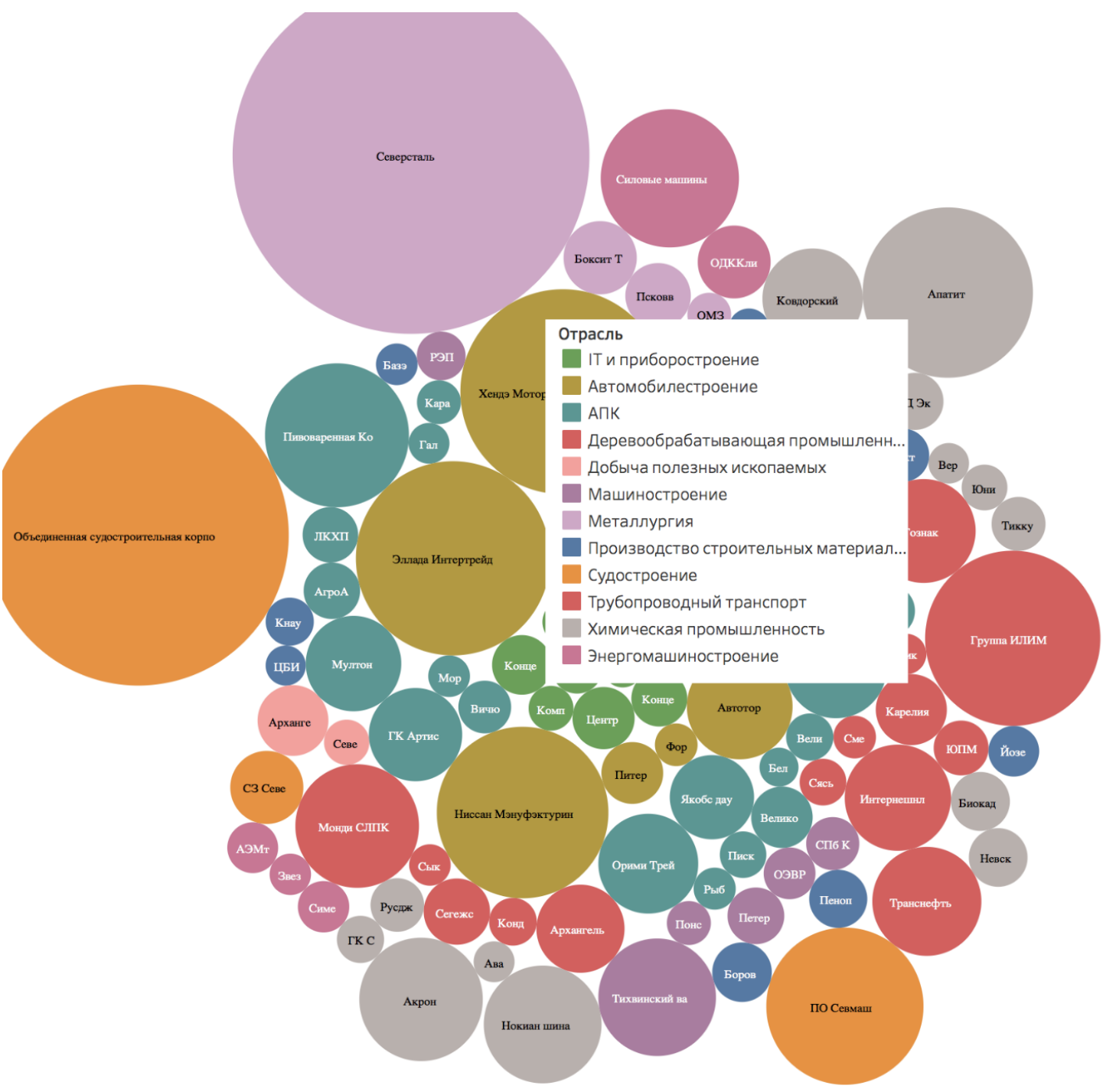

Puc. 1. Карта крупнейших предприятий промышленности СЗФО.

Интерпретировано автором по данным «Эксперт Северо-запад Топ 250»"** 2017.

** Режим доступа http://expertnw.ru/Business-panorama/reyting-top-250-2018 13.12.2018 
промышленного развития СЗФО. Высока также доля деревообрабатывающего сегмента, представленная группой «ИЛИМ», формирующей основной пакет инвестиций в отрасли. Аналогична картина и крупных автомобилестроительных компаний, представляющих локализацию зарубежных ТНК. «Апатит» консолидируют химическую промышленность региона (рис. 1), а «Силовые машины» - энергетическое машиностроение. В свою очередь, инфокоммуникационные технологии и приборостроение имеют низкую консолидацию (по индексу Херфиндаля-Хиршмана) в регионе, что вполне объяснимо стартовой позицией инвестиций в высокие технологии, начальным этапом развития высокотехнологичного сектора Российской Федерации. Но можно выделить и ряд центров кристаллизации высокотехнологичного сектора в регионе, например, предприятия корпорации «Алмаз-Антей».

Предпосылками развития сектора в СЗФО являются наличие развитой инновационной инфраструктуры, человеческого капитала и значимый научно-технический потенциал, выраженный в заделах НИОКР.

Как мы видим, промышленный профиль СЗФО имеет высокую степень диверсификации, что обеспечивает соответствующий уровень кооперации как в производственной, так и научно-технических сферах. Причем научно-техническое развитие является эффективным драйвером всей экономики СЗФО - по итогам 2017 года Санкт-Петербург (административный центр) возглавил рейтинг инновационных городов (по данным «Ассоциации инновационных регионов России»").

Для анализа профиля кластерного развития СЗФО автор скомпилированные «Российской кластерной обсерватории» (организационно оформленные на 2018 год), выделил число отраслевых объединений, предприятий и работников в них входящих, дату образования и уровень развития, табл. 2 .

Для удобства анализа разделены промышленность, социальная сфера, сельское хозяйство и экология. Поскольку объектом исследования является промышленность, автор выделил 2 группы отраслей по сходности уровней объемных показателей численности предприятий и работников кластеров.

Группа 1. Объективно, что наибольшие по размеру (предприятия, персонал) кластеры судостроение, высоких технологий (объединяя группы «электроника и приборостроение» и «информационно-коммуникационные технологии») и «лесоводство, деревообработка, ЦБП». В данных кластерах обнаруживается высокая отраслевая «плотность» - больше 65\% (доля предприятий-резидентов, входящих в кластер). Что свидетельствует об осознанности преимуществ кластерной агломерации, как формы хозяйственного объединения субъектов промышленности, ВУЗов и исследовательских организаций. Таким образом, наблюдается кластеризация промышленного ядра СЗФО, конгруэнтность отраслевого и агломерационного профилей.

Группа 2 включает кластеры машиностроительный, ядерных и радиационных технологий, фармацевтику и медицину, металлургию. Как мы видим, ряд кластеров отражает экономический профиль СЗФО, в частности выделенные отрасли металлургии и перспективных высокотехнологичных - фармацевтику и медицинскую промышленность. Все кластеры находятся на «начальной» стадии хозяйственного объединения, их «плотность» невысока, как и не значителен уровень их внутренней научно-технической и производственной кооперации (менее 7\%). Большинство предприятий кластера ориентируется на внешнего заказчика, консолидированного продукта (построенного на внутренней кооперации) субъектов кластера пока не выражено. Впрочем, все это «нормально» для начальной стадии кластеризации: организационное оформление промышленной агломерации завершено, а хозяйственная кооперация пока не сложилась. Некоторые ученые-экономисты применяют к данной ситуации понятие «протокластера». Анализ состава участников кластеров группы 2 обнаруживает принцип их построения: монопрофильность по виду деятельности. Автор склоняется к точке зрения, что для дальнейшего развития этих кластеров, необходимо применить полиотраслевой принцип объединения: привлекать новых субъектов, находящихся в вертикальной цепочке формирования добавленной стоимости (технологических переделах). Данный подход позволит увеличить внутреннюю научно-техническую и производственную кооперацию кластера, позволяющую реализовать MAR-эффекты промышленной агломерации.

\footnotetext{
* Режим доступа: http://i-regions.org 15.10.2018.
} 
Таблица 2. Кластерная структура СЗФО. Составлено по данным: Российская кластерная обсерватория, 2018". Обозн.: «N»- число кластеров в СЗФО; «S»- число участников, субъектов; «РQ»- численность работников кластера; «Год» - период организационного объединения.

\begin{tabular}{|c|c|c|c|c|c|}
\hline Отраслевая специализация & $\mathrm{N}$ & $S$ & $\mathrm{PQ}$ & Год & Уровень развития \\
\hline \multicolumn{6}{|l|}{ Промышленность } \\
\hline \multicolumn{6}{|l|}{ Группа 1} \\
\hline Судостроение & 2 & 37 & 51572 & 2014 & $\begin{array}{c}\text { Начальный- } \\
\text { средний }\end{array}$ \\
\hline \multicolumn{6}{|l|}{ «Высокие технологии» } \\
\hline Электроника и приборостроение & 1 & 69 & 24662 & 2014 & Начальный \\
\hline Информационно-коммуникационные технологии & 3 & 117 & 23673 & $\begin{array}{l}1999- \\
2014\end{array}$ & $\begin{array}{c}\text { Начальный- } \\
\text { высокий }\end{array}$ \\
\hline Лесоводство, деревообработка, ЦБП & 3 & 78 & 23654 & 2014 & $\begin{array}{c}\text { Начальный- } \\
\text { средний }\end{array}$ \\
\hline \multicolumn{6}{|l|}{ Группа 2} \\
\hline Ядерные и радиационные технологии & 1 & 12 & 13845 & 2014 & Начальный \\
\hline Машиностроение & 1 & 18 & 12316 & 2014 & Начальный \\
\hline Медицинская промышленность & 1 & 39 & 7504 & 2014 & Начальный \\
\hline Фармацевтика & 1 & 13 & 3626 & 2014 & Средний \\
\hline Металлургия & 1 & 13 & 1558 & 2014 & Начальный \\
\hline \multicolumn{6}{|l|}{ Социальная сфера } \\
\hline Туризм & 1 & 27 & 1199 & 2014 & Начальный \\
\hline Социальная сфера & 1 & 18 & 946 & 2014 & Начальный \\
\hline \multicolumn{6}{|l|}{ Сельское хозяйство } \\
\hline Сельское хозяйство & 1 & 27 & 3869 & 2014 & Начальный \\
\hline \multicolumn{6}{|l|}{ Экология } \\
\hline Экология *** & 2 & 49 & 43597 & 2014 & $\begin{array}{c}\text { Начальный- } \\
\text { средний }\end{array}$ \\
\hline
\end{tabular}

* Режим доступа: http://cluster.hse.ru/ 15.10.2018.

** Несмотря на значительные размеры «экологических» кластеров, автор не включает таковые в настоящий анализ экономического профиля региона. Структура предприятий кластера смешанная: ЖКХ, транспорт, центры сортировки, крупные отходообразующие предприятия и т.п. Данная сфера не является моноотраслевой и, тем более, промышленные предприятия не являются якорными для кластеров. Автор не обнаруживает в исследованиях зарубежных прототипов кластеров с аналогичной направленностью. Обнаруживаются промышленные кластеры «вторичной переработки сырья» (сортировка и переработка отходов производства и потребления»), экологическая компонента которых (как это не парадоксально) вторична. Данный вывод согласуется с позицией Алексеева А.А. (2014, [1]).

Итак, можно сделать вывод о соответствии отраслевой структуры кластеров сложившемуся профилю производительных сил и производственных отношений, промышленному профилю Северо-западного федерального округа. Тенденция и перспективы кластеризации оцениваются положительно, с позиции направленности на достижение MAR-эффектов промышленной агломерации. Анализ внутренних процессов кластерного развития СЗФО позволяет автору сформулировать ряд рекомендаций, направленных на перспективу роста экономических эффектов территориального объедине- ния промышленности:

1. Фокус на научно-технической и производственной кооперации субъектов кластеров. Включение соответствующих индикаторов в мониторинг кластерного развития;

2. Полиотраслевой принцип объединения субъектов кластеров. Анализ значимых цепочек добавленной стоимости в экономике СЗФО, выделение и анализ технологических переделов промышленности;

3. Стимулирование отраслевых лидеров (рис. 1) к инициации кластеров, построенных на сложившейся кооперации и субконтракции. 


\section{Библиографический список}

1. Алексеев А.А. Переработка отходов - инновационный сегмент промышленности // Известия СПбГЭУ, № 3 (87), 2014. с. $17-24$

2. Гришин С.Ю., Ткачев В.А. Методические аспекты эффективного проектирования современной системы кластеров в сфере детско-юношеского туризма Северо-западного федерального округа // Журнал правовых и экономических исследований. 2016. № 1. С. 92-98.

3. Лебедева Н.А. Анализ трансформации экономического пространства регионов под воздействием кластерной политики // Инновации. 2014. № 3 (185). С. 86-93.

4. Летовальцева М.А. Формирование кластера как фактора, способствующего повышению конкурентоспособности лесопромышленного комплекса на европейском севере // Экономика и предпринимательство. 2014. № 5-2 (46). С. 283-285.

5. Махотаева М.Ю., Бакуменко О.А. Межрегиональное отраслевое взаимодействие псковской области: кластерный подход // Сервис в России и за рубежом. 2017. Т. 11 . № 7 (77). С. 32-45.

6. Николаев М.А., Махотаева М.Ю. Межрегиональные кластеры как инструмент экономического развития территорий. Научно-технические ведомости Санкт-Петербургского государственного политехнического университета// Экономические науки. 2016. № 1 (235). С. 47-57.

7. Печерица E.B. Потенциал формирования гостиничного кластера в регионах Северо-западного федерального округа. Региональная экономика: теория и практика. 2013. № 20. С. 53-68.

8. Порозов П.Е., Авдеев Ю.М., Мокрецов Ю.В., Хамитова С.М., Лукашевич В.М. Развитие лесного инновационного кластера в регионах СЗФО. Экономика и предпринимательство. 2018. № 1 (90). С. 369-372.

9. Степанова Г.И. Основные концептуальные аспекты развития сельскохозяйственной потребительской кооперации в Северо-западном федеральном округе Российской Федерации // Научное обозрение: теория и практика. 2016. № 4. С. 38-47.

10. Тимошенко С.А. Анализ взаимосвязи программ обучения вузов аграрного профиля и особенностей сельского хозяйства регионов Северо-западного федерального округа Российской Федерации // Известия Санкт-Петербургского государственного аграрного университета. 2017. № 1 (46). С. 222-229.

11. Ускова Т.В., Барабанов А.С., Попова О.И., Иогман Л.Г., Ильин В.В. Производственные кластеры и конкурентоспособность региона. Вологда, 2010. 